\title{
Development of a Fuzzy Inference Based Solar Energy Controller for Smart Marine Water Monitoring
}

\author{
Diana KALIBATIENE $\dot{1}^{1}$, Jolanta MILIAUSKAITÉ ${ }^{2}$, \\ Dale DZEMYDIENË ${ }^{2, *}$, Saulius MASKELIŪNAS ${ }^{2}$ \\ ${ }^{1}$ Department of Information Systems, Faculty of Fundamental Sciences, \\ Vilnius Gediminas Technical University, Sauletekio av. 11, LT-10223 Vilnius, Lithuania \\ ${ }^{2}$ Institute of Data Science and Digital Technologies, Faculty of Mathematics and Informatics, \\ Vilnius University, Akademijos str. 4, LT-08412 Vilnius, Lithuania \\ e-mail:diana.kalibatiene@vilniustech.lt, jolanta.miliauskaite@mif.vu.lt, \\ dale.dzemydiene@mif.vu.lt,saulius.maskeliunas@mif.vu.lt
}

Received: September 2021; accepted: December 2021

\begin{abstract}
Nowadays, there is a lack of smart marine monitoring systems, which have possibilities to integrate multi-dimensional components for monitoring and predicting marine water quality and making decisions for their optimal operations with minimal human intervention. This research aims to extend the smart coastal marine monitoring by proposing a solar energy planning and control component. The proposed approach involves the adaptive neuro-fuzzy inference system (ANFIS) for the wireless buoys, working online during the whole year in the Baltic Sea near the Lithuanian coast. The usage of our proposed fuzzy solar energy planning and control components allows us to prolong the lifespan of batteries in buoys, so it has a positive impact on sustainable development. The novelty and advantage of the proposed approach lie in establishing the ANFIS-based model to predict and control solar energy in a buoy for different lighting and temperature conditions depending on the four year seasons and to make a decision to transfer the collected data. The energy planning and consumption system for the wireless sensor network of buoys is carefully evaluated, and its prototype is developed. The proposed approach can be practically used for environmental monitoring, providing stakeholders with relevant and timely information for sound decision-making about hydro-meteorological situations in coastal marine water.
\end{abstract}

Key words: marine water monitoring, buoys, adaptive neural fuzzy inference system (ANFIS), fuzzy controller, wireless sensor network (WSN), Photovoltaic (PV) system, energy optimization.

\section{Introduction}

In recent years, increasing environmental pollution and human intervention into nature, like wastewater, urbanization, mining, industrialization, and agriculture, have increased the need to study and monitor these adverse effects in marine waters (Aghel et al., 2019;

\footnotetext{
${ }^{*}$ Corresponding author.
} 
Delpla et al., 2015; Behmel et al., 2016). Consequently, smart marine water monitoring methods with application of artificial intelligence (AI) methods for realization of decisionmaking and analysis in the area of water quality monitoring, collecting of water samples and water analysis are needful (Demetillo et al., 2019; Ullo and Sinha, 2020). Moreover, those methods should be implemented into smart systems with combination of multifunctional nodes for obtaining of final goals of marine water quality monitoring. In this research, we understand a smart marine monitoring system as a system with additional AI components. One of the important steps in developing of such complex smart systems is the considering of the energy sources of these systems. Recently, a number of systems can operate on the basis of solar energy, like Mofijur et al. (2019), Tao et al. (2021), Kumar et al. (2020). Consequently, in this paper, we are emphasizing on the usage of solar energy for a smart fuzzy system of marine water quality monitoring.

Therefore, the aim of this research is to develop the smart fuzzy inference based solar energy planning and control component for coastal marine water monitoring. The usage of the proposed smart fuzzy inference based solar energy planning and control component (Smart-SolE) allows us to prolong the lifespan of batteries in buoys, so it has a positive impact on sustainable development that responds to the main Sustainable Development Goals (SDG) of Agenda'2030 (Colglazier, 2015), and Green Deal'2030 Strategy (European Commission, 2019).

Recently, researchers have used heuristic artificial intelligence-based algorithms that can estimate and present the potential energy of system loads from nonlinear solar energy (Sarkar et al., 2021). Liu et al. (2021) in their proposed method for power management consider the effects of variation of temperature, radiation, output load, and use Type-3 fuzzy system. For future works, authors have left the issues of stability. Padmanaban et al. (2019) have used a hybrid ANFIS-ABC swarm intelligent control for power point tracking in the photovoltaic (PV) system with grid integration, Mosavi et al. (2020) - Type-3 fuzzy system for energy/voltage management in PV/battery systems. González-Reolid et al. (2018) have proposed BUSCAMOS-RobObs for water quality monitoring in lakes and shallow coastal waters. Their proposed approach improves the autonomy in monitoring water quality parameters and avoids the deployment of a large number of buoys. In order to minimize the energy consumption, authors have used fuzzy goal management system, which considers the state of batteries and the distance to alternative exploration areas to select the next mission zone.

Recently, the fuzzy set theory has emerged as a powerful technique in the analysis and decision making in water quality analysis of open resources and hydrology (Kambalimath and Deka, 2020). It allows to consider the handling of vagueness (or ambiguity) in hydrology (Bogardi et al., 2004), like lack of data, nature causes (e.g. climate), imprecise modelling of changing phenomenon of mixing and transitional waters, etc. A number of authors in different areas of application have presented the suitability and applicability of fuzzy set theory, like Zimmermann (2001), Tamir et al. (2015), Verma and Merigó (2020), etc.

According to Ighalo et al. (2021), the Adaptive Neuro-Fuzzy Inference System (ANFIS) and Artificial Neural Networks (ANN) are the most utilized AI models for water 
quality monitoring and assessment systems, which include the usage of solar energy, in the last decade. The advantages of using AI methods in various monitoring and assessment application areas are that they are faster and more efficient than linear mathematical or statistical methods, low-cost, can be used for real-time monitoring (Yetilmezsoy et al., 2011; Ighalo et al., 2021; Demetillo et al., 2019), and ensure lower error values in prediction (Karaboga and Kaya, 2019).

The usage of ontologies for marine sensor networks is expanding nowadays. The joint World Wide Web Consortium (W3C) and Open Geospatial Consortium (OGC) Spatial Data on the Web (SDW) Working Group developed a set of ontologies to describe sensors, actuators, samplers, as well as their observation, actuation, and sampling activities. The ontologies have been published both as a $\mathrm{W} 3 \mathrm{C}$ recommendation and as an OGC implementation standard. The set includes a lightweight core module called SOSA (Sensor, Observation, Sampler, and Actuator), and a more expressive extension module called SSN (Semantic Sensor Network). Together they describe systems of sensors and actuators, observations, the used procedures, the subjects and their properties being observed or acted upon, samples and the process of sampling, etc. (W3C, 2017; Haller et al., 2019). The SOSA ontology was developed based on SSN ontology and taking into account the changes in scope and target audience, technical developments, and lessons learned over the past years. It provides a formal but lightweight general-purpose specification for modelling the interaction between the entities involved in the acts of observation, actuation, and sampling (Janowicz et al., 2019). Marine ecology ontology repository is presented in Yun et al. (2015), which implements marine ecological knowledge navigation, term query, knowledge retrieval and ecological crisis early warning. Moreover, ontologies are useful in capturing domain causality as the internal domain model (Gudas, 2021), to eliminate conceptual ambiguity and semantic gap in information security (Iqbal and Matulevičius, 2020), etc.

The proposals for developing of mobile buoy systems and integrating of different kinds of sensors for hydro-meteorological monitoring purposes of marine water are presented in works (Dzemydienè et al., 2021; Gricius et al., 2015; Lin et al., 2017). The heterogeneous sensors are implemented in the buoy system and can observe the water surface elevations by providing the real-time tide and wave data in estuaries and coastal areas (Lin et al., 2017; Zoss et al., 2018). The distributed system of autonomous buoys for scalable deployment and monitoring of coastal waterbodies have had a dynamic cooperative array of mobile buoys afforded with sensing capabilities (Dzemydienè and Radzevičius, 2020; Zoss et al., 2018). The mobile buoy system, described in Helmi et al. (2014), can work remotely controlled by a computer which sends a series of commands to Intel Atom N2600 Board and microcontrollers over Global System for Mobile Communication (GSM). Authors describe the monitoring of water quality in continental, coastal areas and in lakes.

In this research, we are focusing on the solar energy usage for a smart fuzzy system of marine water monitoring of the Baltic Sea region in the coastal waters of Lithuania. The peculiarities of four seasons (winter, spring, summer, and autumn) in the Baltic Sea region are observed, i.e. air temperature, solar irradiance and their ratio change significantly. That gives the experiment its uniqueness, and requires additional testing and system calibration. 
The novelty of the present research lies in establishing an ANFIS-based model to predict and control solar energy in a solar buoy for different lighting and temperature conditions depending on the four seasons (autumn, winter, spring and summer). Furthermore, the proposed model has been implemented in a smart fuzzy coastal marine water monitoring system (Smart-MarineM) for estimation of a current power of a solar battery, lighting and temperature conditions and to make a decision to transfer the data.

The structure of the paper is as follows. Section 2 presents Related works. Section 3 describes the developed smart fuzzy system of marine water monitoring including fuzzy inference based solar energy planning using ANFIS. Section 4 presents the results of the implementation of the proposed approach and experiments. Section 5 presents Discussion, and Section 6 concludes the paper.

\section{Related Works}

In this section, we review papers dealing with the usage of solar energy (or irradiation) for a smart marine water quality monitoring.

Vo et al. (2021) have presented a review on the Internet of Things (IoT) technologies in controlling ocean environment. They have concluded that almost all the existing ocean environment control applications gathered and analysed extensive data from the marine environment, however, marine environmental monitoring activities to protect marine ecosystems were still very limited. According to Vo et al. (2021), the usage of AI in such systems allows us to enable more accurate and flexible data collection. Moreover, the application of big data and real-time parallel with 5G network technology is convenient for marine environmental control centres to access, process, and analyse the received data with ultra-high spatial and temporal resolution so that solutions can be issued to fix unexpected events immediately.

In Cho et al. (2021), it is argued that recent demand for eco-friendly energy sources has been rapidly increasing. Therefore, the Lithium-ion battery (LIB) exposed to seawater or corroded by immersion is not suitable for marine buoys because its cobalt toxicity causes serious environmental pollution problems (Olivetti et al., 2017). Consequently, a number of authors have proposed to use seawater batteries (Cho et al., 2021; Ligaray et al., 2020; Zhang et al., 2018; Hwang et al., 2019; Kim et al., 2021) or solar batteries (Przybysz et al., 2020; Zhang et al., 2021; Trevathan and Sharp, 2020) for wireless marine buoy systems. However, as indicated in Cho et al. (2021), Demirdelen et al. (2019), there are some issues to be resolved when using those batteries as follows: 1) proper support charge during battery usage; 2) maintaining stable battery state by preventing overcharge and undercharge; 3 ) for lifetime or optimal replacement time estimations, the degradation progress in the battery needs to be reported. Moreover, the marine buoy needs to be selfpowered with harvesting devices such as PV (Helmi et al., 2014), wind (Kesavakumar et $a l ., 2013$ ) and wave harvester (Li et al., 2019) for long-lasting system operation. Also, intelligent power management techniques are required, since the buoy lightening causes large power consumption. 
Demirdelen et al. (2019) have reviewed different solar power prediction methods in order to obtain more accuracy. They have determined, that in real-time operation systems, i.e. buoys, a short time prediction is used.

Morón-López et al. (2020) have implemented a Remote Monitoring System (RMS) based on IoT technologies combined with satellite imagery, track harmful algae blooms (HABs) in two Spanish waters: the freshwater (Conchas Reservoir (Galicia)) and the brackish water shallow (L'Albufera Lagoon (Valencia)). The authors concentrate on data collection from two different environments, data transfer to a data management system on the cloud and their visualisation on the web interface in real time and do not describe battery power management.

Falleni et al. (2020) have proposed a Smart Buoy for real-time remote access to underwater devices and for provision of power and extended computational capabilities. Its Power Module houses a central battery unit and a solar panel that together offer the buoy long periods of autonomy while deployed. The module also includes a solar charge controller that prevents over-charging and over-discharging of the battery, and voltage regulators and electric switches that power on and off the other components while performing energy-saving when possible. Consequently, the Power Module does not have an intelligent component and is relatively simple. However, their experiments showed that the Smart Buoy operates properly.

In the proposed Floating Water Quality Monitoring using IoT System (Thamrin et al., 2021), a self-power embedded controller is used. The power storage could provide enough for the entire system to operate with optimum voltage and current for 24-hour operation.

In Sabatini et al. (2021), a sensor network for inland water monitoring based on buoys embedded with the reduced size and power consumption release of the BIONOTE-L is presented.

Darmawan et al. (2020) have designed the detection device for seawater waves with fuzzy algorithm based on IoT. Authors investigated the possibilities to combine a gyroscope, which detect and measure the angular motion of waves, an accelerometer, which measures the acceleration of the force of waves, and LoRa (i.e. Long Range and proprietary low-power wide-area network modulation technique), which became useful for developing of a low-power wireless technology that uses radio spectrum (Darmawan et al., 2020). Authors are trying to implement the fuzzy set theory to predict the tsunami waves at sea. However, they do not present a fuzzy reasoning system in details. Only fuzzy calculations are presented in the paper. Moreover, the proposed system testing during the medium and dangerous environment conditions is not clear. The observations are devoted for inland waters, but have no analysis of possibilities for developing of online working buoy systems with the implementation of solar energy in small devices.

The mobile buoy systems for water quality monitoring are presented in Zoss et al. (2018). Similar structures of systems are developed as a GNSS buoy and have possibility to observe the water surface elevations and provide the real-time tide and wave data in estuaries and coastal areas in Lin et al. (2017), Dzemydienè and Radzevičius (2020). The problem of distributing of operations is considered in Zoss et al. (2018). The system consists of a dynamic cooperative array of mobile buoys afforded with sensing capabilities. The possibilities to use the solar energy are omitted, and we see the need to apply 


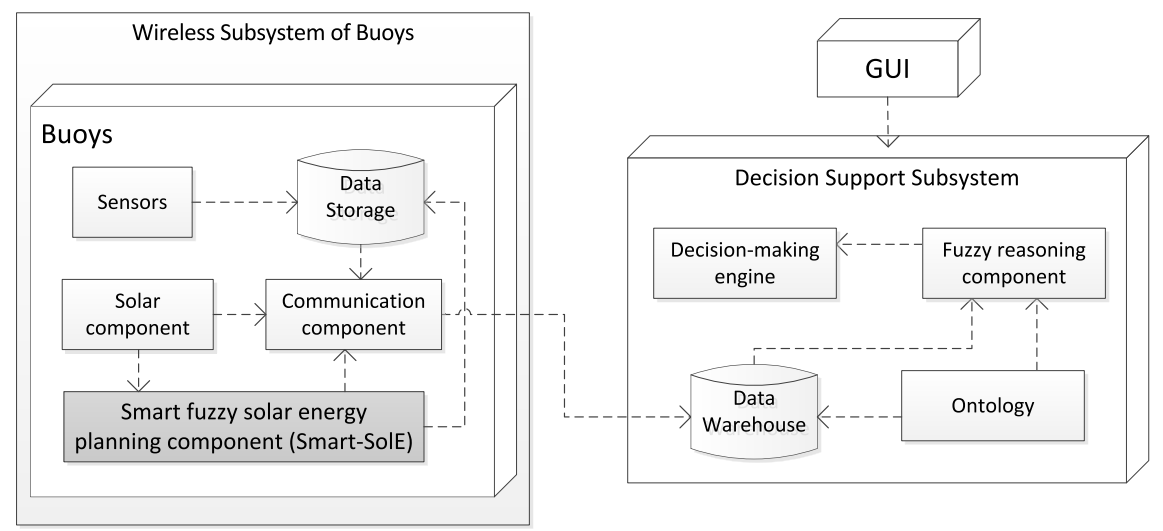

Fig. 1. The reference architecture of the smart fuzzy coastal marine water monitoring system (Smart-MarineM).

the intelligent components like fuzzy reasoning and ANFIS for predicting, planning and maintaining the energy of a smart system.

The controller based on the adaptive fuzzy neural network to track the dynamically positioned vehicle on water with unavailable velocities and unidentified control parameters is presented by Zhang et al. (2020). Qin et al. (2019) have solved the problem of missing data due to transmission errors by using sensor's failure and equipment's maintenance methods in buoy-based monitoring system. Song et al. (2021) are trying to present the continuous space location model and a particle swarm Optimization-Based Heuristic Algorithm for maximizing the allocation of ocean-moored buoys.

Summing up, the topic of exploring marine environment using different smart marine water quality monitoring systems is relevant and expands in the way of using IoT and cloud technologies for better data transmission and processing. However, the topic of intelligent solar energy (or irradiation) management system for a marine water quality monitoring remains insufficiently examined. Almost all found buoy systems for marine water monitoring are equipped with linear solar power control systems. Meanwhile, while solar energy management systems based on ANFIS (Abadi et al., 2018; Viswavandya et al., 2020) are proposed in other application domains, ANFIS employment in buoys for solar energy monitoring remains little examined.

\section{Development of the Smart Fuzzy System of Marine Water Monitoring}

The overall reference architecture of the smart fuzzy coastal marine water monitoring system (Smart-MarineM) is presented in Fig. 1. The Smart-MarineM is designed with its main goal of coastal marine water hydro-meteorological data monitoring with the consideration that the system: 1) can measure and store information in a Data Storage in a real-time scenario; 2) adopts to the solar energy consumption (the Smart fuzzy solar energy planning and control component (Smart-SolE)); 3) is suitable for intelligent data 
transfer to the Smart monitoring node; 4) is suitable for smart energy planning and control using ANFIS.

\subsection{The Reference Architecture of Smart-MarineM}

The most important function of the system is to ensure that the data collection from the Sensors reflect the actual aquatic status and the data are transmitted and delivered to the Data Warehouse of the Decision Support Subsystem in a timely manner using Communication component. Solar component (consisting of a Solar panel - energy generator, and a battery) ensures the delivery of energy to the buoy. The Decision Support Subsystem is responsible for processing of the data from Data Warehouse using the Fuzzy reasoning component, which evaluates overall situation of water quality and transfers results to Decision-making engine. The Ontology component is used for the description of data in the Data Warehouse. The usage of Ontology in our system facilitates conceptualization and smooth mapping between concepts to assist in structuring the domain knowledge; ensures explicit domain assumptions and unambiguous interpretation of both the concepts and their interrelationships by the Fuzzy reasoning component; assists more intelligent search (e.g. generalization of queries to find nearest partial matches). With the help of Ontology, the marine water monitoring system becomes more apprehensible, better prepared to any further changes and modifications required.

The Data Storage component is used for storage of temporal data from Sensors in the case when buoys cannot transmit the data to the Data Warehouse because of low battery.

Users are gathering the information through the graphical user interface (GUI) from the Smart-MarineM about hydro-meteorological situations of coastal marine water, some kinds of decisions or/and control actions.

The hardware background of the subsystem of buoys under development consists of the following four layers (Dâmaso et al., 2014; Gricius et al., 2015; Dzemydienè and Radzevičius, 2020):

- the network layer as a background layer of computing nodes that guarantees the ability of the system to be able of working and ensuring communication between nodes (buoys) and a master node (a stationary working host machine) in a decentralized wireless way;

- the protocol layer, which consists of fundamental communication technologies, such as consensus algorithms, cryptography methods, ensuring that the system on-line work properly;

- the wireless sensors network (WSN) layer that is responsible for the primary data monitoring mission by transmitting transactions securely and assures that existing system functions are working correctly;

- the application layer, which provides APIs for the object's usability and is responsible for interaction with the other buoys and users in the network.

An infrastructure of distributed buoys with integrated multi-function sensors should be created to support online and real-time operation of cooperative components, with limited power supply and memory capacity. 
Table 1

Components which are integrated into the structure of buoy's system based on WSN.

\begin{tabular}{|c|c|c|}
\hline No. & Name and type of component & Functionality description \\
\hline 1 & $\begin{array}{l}\text { Arduino Mega control board with } \\
\text { ATMega2560 microcontroller }\end{array}$ & $\begin{array}{l}\text { It works at } 16 \mathrm{MHz} \text { clock speed and is the main block } \\
\text { supporting the infrastructure of buoys. }\end{array}$ \\
\hline 2 & SIM900 network module & $\begin{array}{l}\text { It is responsible for wireless communication and data } \\
\text { transmission via GSM network to the monitoring station. }\end{array}$ \\
\hline 3 & $\begin{array}{l}\text { The geographical positioning system } \\
\text { (GPS) }\end{array}$ & $\begin{array}{l}\text { It is used for recognition of coordinates (i.e. latitude and } \\
\text { longitude) of buoys. }\end{array}$ \\
\hline 4 & $10 \mathrm{~mW}$ XBee PRO module & $\begin{array}{l}\text { It is responsible for providing wireless communication } \\
\text { between individual buoys. }\end{array}$ \\
\hline 5 & $\begin{array}{l}\text { Connection of sensors (like the MPU6050 } \\
\text { accelerometer/gyroscope pair) }\end{array}$ & It is working as sensors of waviness measurements. \\
\hline 6 & Real time control (RTC) timer & $\begin{array}{l}\text { It works as a timer for measuring time durations, and supports } \\
\text { the control of working regime according to the supply energy } \\
\text { and consumptions needs. }\end{array}$ \\
\hline 7 & $\begin{array}{l}\text { The connection structure for integration of } \\
\text { other type sensors }\end{array}$ & $\begin{array}{l}\text { Heterogeneous block for connection of sensors in a buoy, like } \\
\text { temperature, barometric pressure and other sensors. }\end{array}$ \\
\hline 8 & Power supply block & $\begin{array}{l}\text { Each buoy is powered by solar energy, which can be charged } \\
\text { in Ni-MH type batteries at the same time, allowing the buoy } \\
\text { to operate during the dark and light hours throughout the day. }\end{array}$ \\
\hline 9 & $\begin{array}{l}\text { Global System for Mobile communication } \\
\text { (GSM) antenna }\end{array}$ & For Mobile Wi-Fi communication. \\
\hline
\end{tabular}

In this study we have focused on the smart fuzzy solar energy planning component, which is important for autonomous work of buoys subsystem. The prototype of smart system under development is working on the basis of WSN for continuous data transmitting. The hardware part of the subsystem of buoys is based on some sets of components which are integrated in the whole system. A possible description of components that can be integrated into the buoy system is presented in Table 1 .

Each buoy can have from 1 to 20 sensors that gather different data at time intervals, which are defined in Smart-MarineM.

\subsection{ANFIS for Solar Energy Planning}

\subsubsection{The ANFIS Structure}

The adaptive neuro fuzzy inference system (ANFIS), composed of the fuzzy inference system (FIS) and the artificial neural network (ANN), solves non-linear problems with enhanced performance. The FIS component conveys the qualitative human thinking process into the accurate quantifiable evaluation. The ANN component is responsible for learning (using training data sets) and adapts to its environment. ANFIS is based on premise and consequence parts, which are connected using IF-THEN fuzzy rules (Eq. (1)):

$$
R_{i}: \text { if }\left(x_{1} \text { is } A_{1}^{i}\right) \ldots \text { and } \ldots\left(x_{n} \text { is } A_{n}^{i}\right) \text { then } f_{i}=a_{i}^{T} \cdot x+b_{i},
$$

where $\left(x \in \mathbb{R}^{n}\right)$ are input variables of fuzzy sets $A_{1}^{i}, \ldots, A_{n}^{i}$, and $\left(a_{i}, b_{i}\right)$ are the design parameters that are determined during the training process using a linear Takagi-Sugeno model (Takagi and Sugeno, 1985). The ANFIS structure consists of five layers (Fig. 2). 


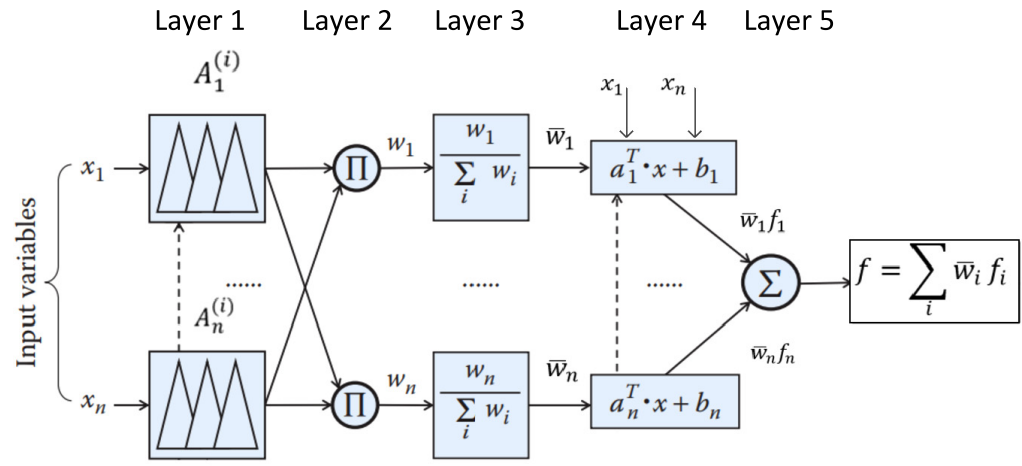

Fig. 2. The basic ANFIS structure.

In this study, we have used two inputs and one output of ANFIS structure. In the first layer (Layer 1, Fig. 2), two inputs $\left(\left(x_{1}, x_{2}\right), n=2\right)$, i.e. voltage parameter and current are fuzzified by using the triangular membership function (MF) (Eq. (2)) and provided to the second layer (Layer 2).

In this study, we have used triangular MF, since it is easily implementable in FIS (Miliauskaitè and Kalibatiene, 2020a, 2020b; Kalibatienè and Miliauskaitè, 2021; Choi and Rhee, 2009).

$$
\mu_{A_{i}}(x)= \begin{cases}0, & \text { if } x<c_{1}, c_{3} \leqslant x, \\ \frac{x-c_{1}}{c_{2}-c_{1}}, & \text { if } c_{1} \leqslant x<c_{2}, \\ \frac{c_{3}-x}{c_{3}-c_{2}}, & \text { if } c_{2} \leqslant x<c_{3},\end{cases}
$$

where: $c_{1}, c_{2}, c_{3}$ are the adaptive parameters of the function.

The second layer (Layer 2) assesses the fuzzing inputs, evaluates the weights for the MFs and provides the strength parameters $w_{i}$ (Eq. (3)) to the third layer (Layer 3), which normalizes the weights $\left(\bar{w}_{i}\right)$ of the MF using Eq. (4).

$$
\begin{aligned}
w_{i} & =\prod \mu_{i}(x), \\
\bar{w}_{i} & =\frac{w_{i}}{\sum_{i} w_{i}} .
\end{aligned}
$$

The third layer (Layer 3) provides the normalized weights $\left(\bar{w}_{i}\right)$ of MFs to the fourth layer (Layer 4), which applies fuzzy rules (Eq. (1)) to obtain $f_{i}$, performs the product of the normalized weights $\left(\bar{w}_{i}\right)$ and $f_{i}$, and provides the final results to the fifth layer (Layer 5). In Layer 5, the global model response $(f)$ is calculated by Eq. (5).

$$
f=\sum_{i} \bar{w}_{i} f_{i}
$$

Training of ANFIS means determining the parameters in its structure in Layer 1 and Layer 4 using an optimization algorithm. In the training phase, Layer 1 (i.e. premise) and 


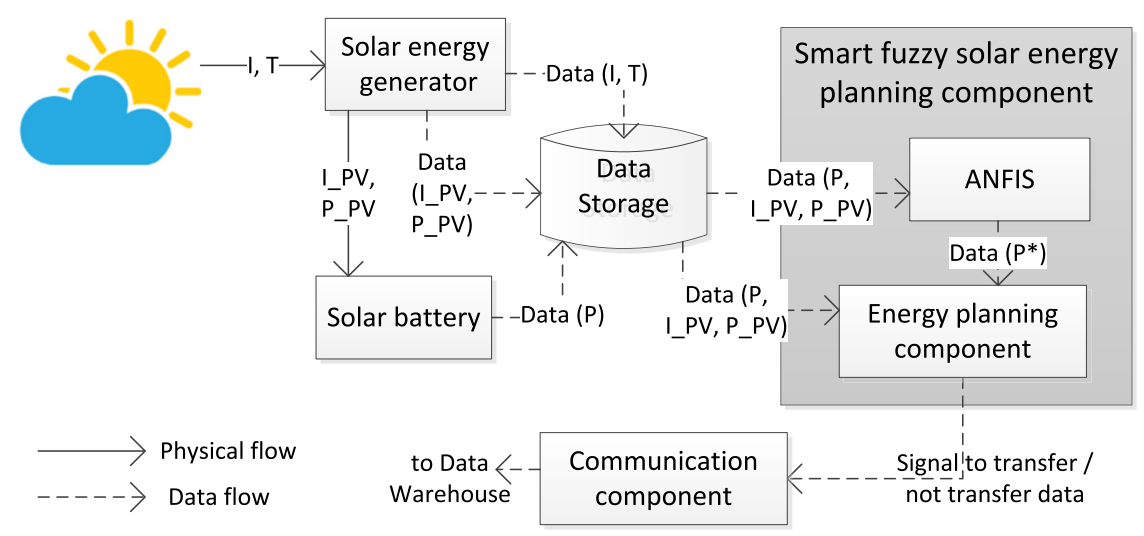

Fig. 3. The proposed Smart-SolE (I - Irradiation $\left(\mathrm{W} / \mathrm{m}^{2}\right), \mathrm{T}-$ Temperature, ${ }^{\circ} \mathrm{C}, \mathrm{P}-$ power, $\mathrm{W}$, generated by Solar energy generator, $\mathrm{P}^{*}$ - power, W, predicted by ANFIS, I_PV - current, A, P_PV - voltage, V).

Layer 4 (i.e. consequence) parameters are utilized in order to obtain effective results. Different training approaches have been suggested to achieve better performance of ANFIS (Karaboga and Kaya, 2019). In our study, we have used a hybrid approach.

After the training is complete, the performance of ANFIS is determined by a set of different algorithms. In our case, we have used the mean squared error (MSE) (Eq. (6)) to measure the average of the squares of errors between the outputs $f_{i}$ and the training sets $f_{\text {train }}$.

$$
M S E=1 / n \sum_{i=1}^{n}\left(f_{i}-f_{\text {train }_{i}}\right)^{2}
$$

where $f_{i}$ and $f_{\text {train }}$ denote the ANFIS output and the measured value from the $i$-th element. The closer MSE is to zero, the more accurate the predicted result.

\subsubsection{Smart Fuzzy Solar Energy Planning Using ANFIS}

The proposed Smart fuzzy solar energy planning component (Smart-SolE) with ANFIS for solar energy usage evaluation is presented in Fig. 3.

The operation of the proposed system is presented in Fig. 4. The system starts operating within the predefined time periods. However, this interval can be changed by the administrator or the Decision Support Subsystem (see Fig. 1) in case of emergency or the need. If the Energy planning component based on the ANFIS prediction results determines that the Solar battery is charged enough, then it sends a signal to the Communication component for transfer of data collected by Sensors to the Decision Support Subsystem. If there is not enough power for data transfer, the Smart solar energy planning component is in the mode of waiting for enough power. However, in the waiting mode the newly collected portions of data by the Solar energy generator are stored in the Data Storage. 


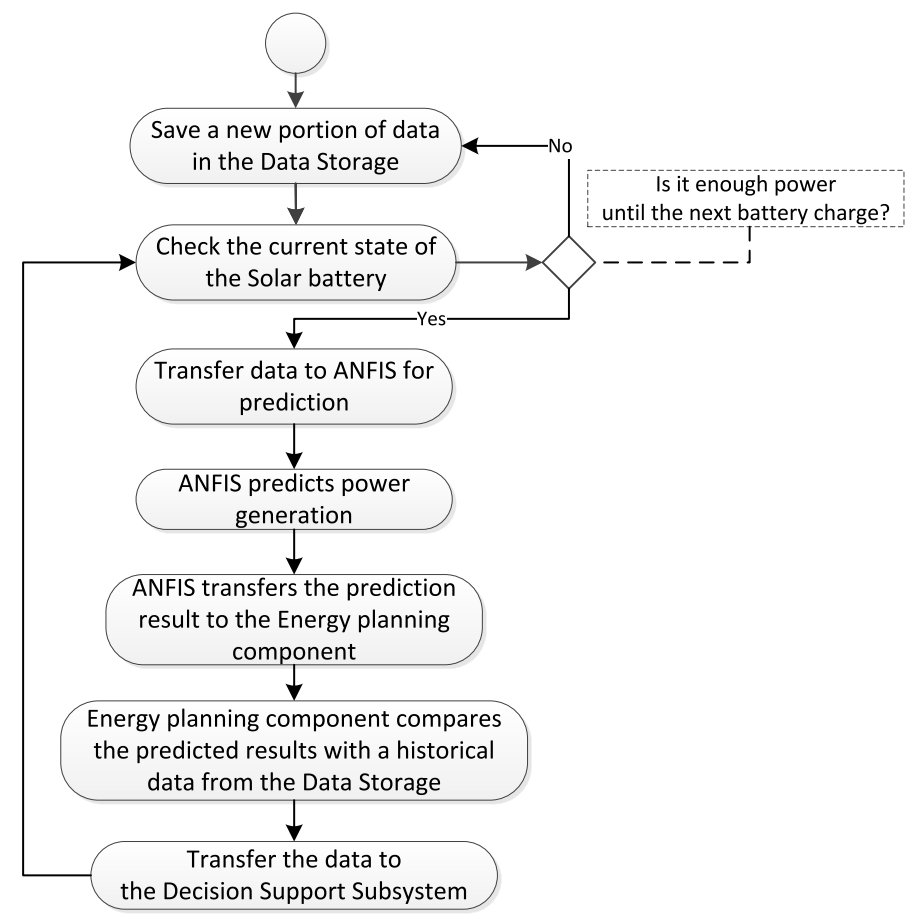

Fig. 4. The algorithm of the proposed Smart-SolE.

Table 2

"SAM-150P" solar module specification and electrical parameters.

\begin{tabular}{ll}
\hline Parameters & Specification \\
\hline Cells per module (NCell) & 36 \\
Maximum power per module $\left(\mathrm{P}_{\mathrm{mp}}\right)$ & $150 \mathrm{~W}$ \\
Voltage of maximum power point $\left(\mathrm{V}_{\mathrm{mp}}\right)$ & $18.38 \mathrm{~V}$ \\
Current at maximum power point $\left(\mathrm{I}_{\mathrm{mp}}\right)$ & $8.16 \mathrm{~A}$ \\
Open circuit voltage $\left(\mathrm{V}_{\mathrm{oc}}\right)$ & $22.68 \mathrm{~V}$ \\
Short-circuit current $\left(\mathrm{I}_{\mathrm{sc}}\right)$ & $8.62 \mathrm{~A}$ \\
Temperature coefficient of $\mathrm{V}_{\mathrm{oc}}$ and $\mathrm{I}_{\mathrm{sc}}\left(\% /{ }^{\circ} \mathrm{C}\right)$ & $-0.34 /+0.08$ \\
\hline
\end{tabular}

\section{Experimental Research Results}

The proposed approach was implemented into the Smart-SolE prototype for evaluation and exam using the MATLAB/Simulink 2021 software. The buoys network at the Baltic Sea and Lithuanian coastal hydro-meteorological data ${ }^{1}$ were used in the experiments. The buoys network solar module technical parameters are presented in Table 2.

The collected measurement data used in the experiments consists of two data sets as following: 1) a data set about weather conditions in the period of five years including

\footnotetext{
${ }^{1}$ http://www.meteo.lt/lt/menesio-apzvalgu-archyvas.
} 


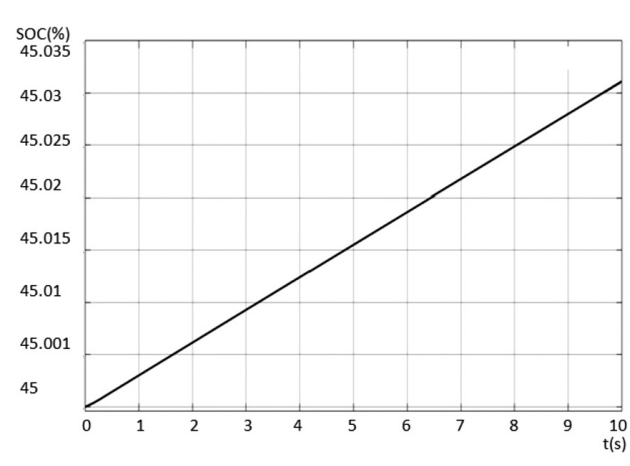

a)

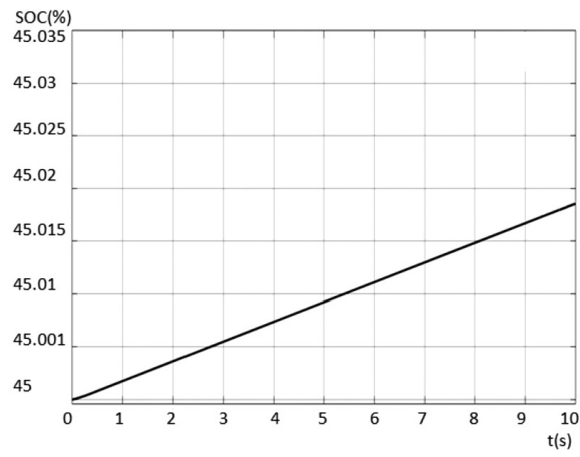

b)

Fig. 5. The battery charging level (\%): a) partial shading conditions during the spring and autumn $(\mathrm{I}=970$ $\left.\mathrm{W} / \mathrm{m}^{2}, \mathrm{~T}=+9.7^{\circ} \mathrm{C}\right)$; b) the least sunny conditions during the winter $\left(\mathrm{I}=538 \mathrm{~W} / \mathrm{m}^{2}, \mathrm{~T}=-1.1^{\circ} \mathrm{C}\right)$.

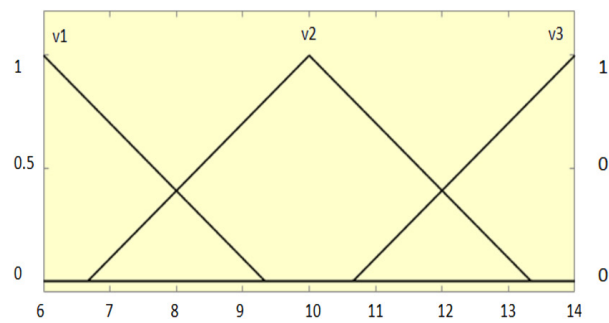

a)

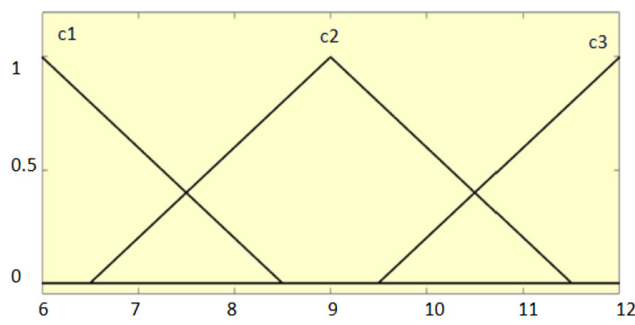

b)

Fig. 6. The inputs: a) PV voltage (I_PV) MFs; b) PV current (P_PV) MFs.

four seasons ${ }^{1}$ (temperature $\left({ }^{\circ} \mathrm{C}\right)$, irradiation $\left(\mathrm{W} / \mathrm{m}^{2}\right)$ ); and 2) a data set collected from the hydrographic buoy (irradiation $\left(\mathrm{W} / \mathrm{m}^{2}\right)$, temperature $\left({ }^{\circ} \mathrm{C}\right)$, humidity $(\%)$, battery voltage (V)).

The Smart-SolE prototype simulated different operating conditions, i.e. various irradiation conditions depending on the seasons, and was tested to study its operation. We have examined three different working conditions as follows: 1) the high lighting conditions during the summer, when the average irradiation is $1042 \mathrm{~W} / \mathrm{m}^{2}$, and the average air temperature is $+17.9^{\circ} \mathrm{C}$; 2) the partial lighting conditions during the spring and autumn, when the average irradiation ${ }^{1}$ is $970 \mathrm{~W} / \mathrm{m}^{2}$, and the average air temperature is $+9.7^{\circ} \mathrm{C}$; and 3 ) the least sunny conditions during the winter, when the average irradiation ${ }^{1}$ is $538 \mathrm{~W} / \mathrm{m}^{2}$, and the average air temperature is $-1.1{ }^{\circ} \mathrm{C}$. In this paper, we present the most interesting cases (i.e. the partial lighting (Fig. 5a) and the least sunny (Fig. 5b) conditions) as follows. In figures, the $x$-axis shows the time of battery charging in seconds; the $y$-axis presents the battery charging level in percentages. Note that initial battery charging level taken in the experiment is $45 \%$.

As can be seen from Fig. 6, in the least sunny period the battery charging speed is lower. Two inputs of the form of power and voltage data (PV array), i.e. system voltage (I_PV) and current (P_PV), are provided to ANFIS (Fig. 3). 


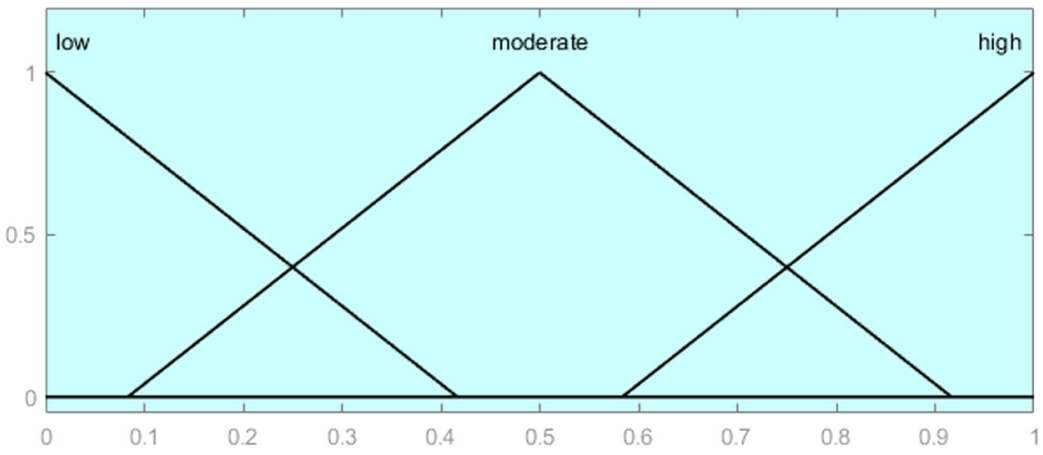

Fig. 7. The output Power $\left(\mathrm{P}^{*}\right) \mathrm{MFs}$.

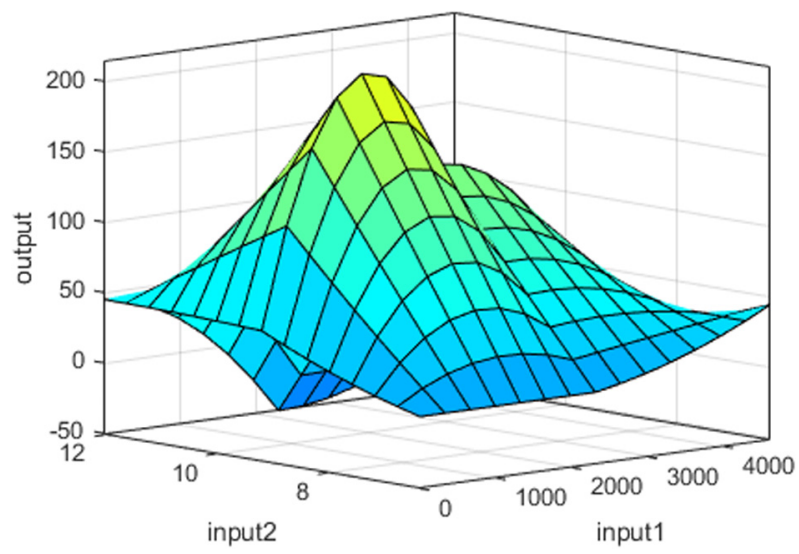

Fig. 8. The dependency between input (input 1 (I_PV), input 2 (P_PV)) and output Power ( $\left.\mathrm{P}^{*}\right)$ parameters.

Note that voltage, current and power in the measurement stage are labelled as V, I and P, respectively; and, in Smart-SolE, they are labelled as voltage (I_PV) and current (P_PV).

We present the result of prediction during the winter, since it is the least sunny period in the year. The inputs consist of 3 MFs each, and the MFs are of triangular nature. From the training data set, it is observed that the voltage parameters vary from 6 to $14 \mathrm{~V}$ (Fig. 6a) and the current parameters vary from 6 to $12 \mathrm{~A}$ (Fig. 6b).

According to the presented input (voltage and current), ANFIS predicts power $\left(\mathrm{P}^{*}(\mathrm{~W})\right)$, the MFs of which are presented in Fig. 7.

The relationships between two-input and one-output of ANFIS can be depicted by a 3 -D plot. The surface model in Fig. 8 represents the input-output dependency. The $x$-axis represents voltage (I_PV) (input 1), the $y$-axis is the current (P_PV) (input 2), and the $z$-axis is the value of power (output). How the output depends on the input is determined by the fuzzy rules (see the explanation below).

In this research, using two-input parameters with three fuzzy sets per input, FIS has produced a complete rule set of $9\left(3^{2}\right)$ rules in order to build an ANFIS model. It is im- 
Table 3

ANFIS training and testing settings.

\begin{tabular}{ll}
\hline Parameter & Description/Value \\
\hline Fuzzy structure/FIS training data & Sugeno/genfis1 \\
FIS object generation & grid partition on the data \\
MF type of Input/MF type of Output & trimf (triangular)/constant \\
Number of inputs/outputs & $2 / 1$ \\
Number of MFs associated with each input & 3 \\
Optimization method & hybrid \\
Training algorithm to model the training data & least-squares and backpropagation gradient descent methods \\
Maximum number of training epochs & 100 \\
Initial step size & 0.001 \\
Step size decrease rate/increase rate & $0.9 / 2$ \\
Data for training/data for testing & $70 / 30$ \\
\hline
\end{tabular}

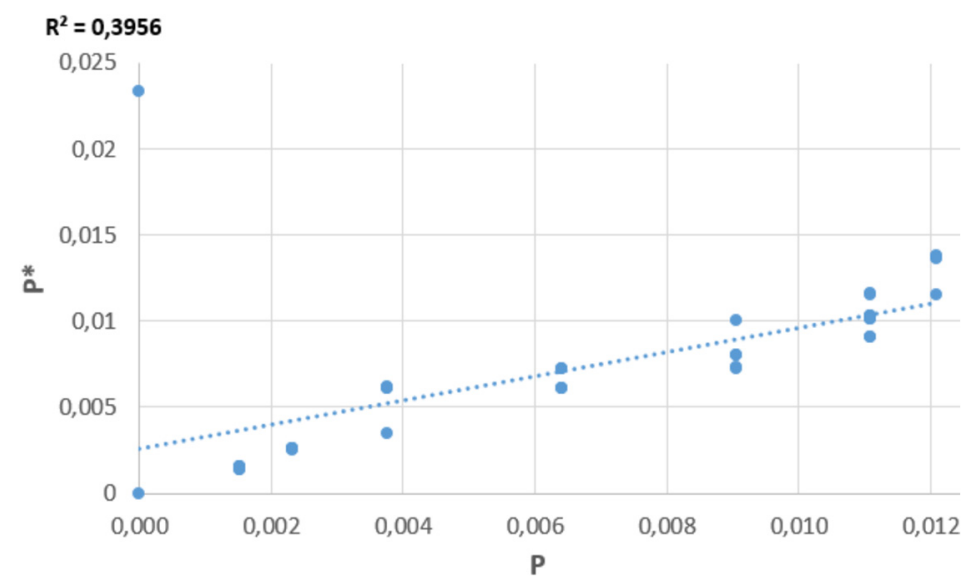

Fig. 9. The output of $\mathrm{P}^{*}$ after processing in ANFIS - results of training.

portant to note that the partition increase of the input space exponentially increases the number of rules that influence and enormously enlarge the speed of learning and application of the system. Therefore, an effective partition of the input should be found.

Some examples of the fuzzy rules are as follows:

IF (P_PV is Low) AND (I_PV is Low) THEN ( ${ }^{*}$ is Low);

IF ( $P$ _PV is Low) AND (I_PV is High) THEN ( $\mathrm{P}^{*}$ is Moderate);

IF ( $P$ _PV is Moderate) AND (I_PV is Low) THEN ( $P^{*}$ is Moderate);

IF ( $P$ _PV is Low) AND (I_PV is Moderate) THEN ( $P^{*}$ is Low).

The ANFIS settings for this study are presented in Table 3.

Figures 9 and 10 present the results of dataset processing by ANFIS during the winter. We have used 70/30 ratio for the training and testing.

As can be seen, $\mathrm{P}^{*}$ becomes more accurate after training, i.e. during training the coefficient of determination is $R^{2}=0.3956$, during testing $R^{2}=0.8371 . R^{2}$ describes the degree of association between experimental data and those obtained by the model. In the 


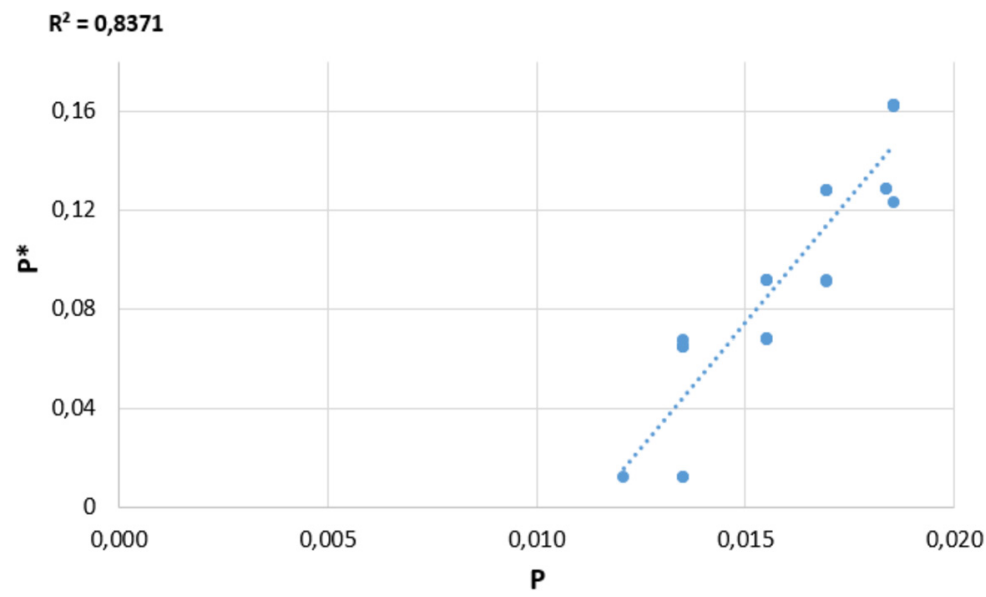

Fig. 10. The output of $\mathrm{P}^{*}$ after processing in ANFIS - results of testing.

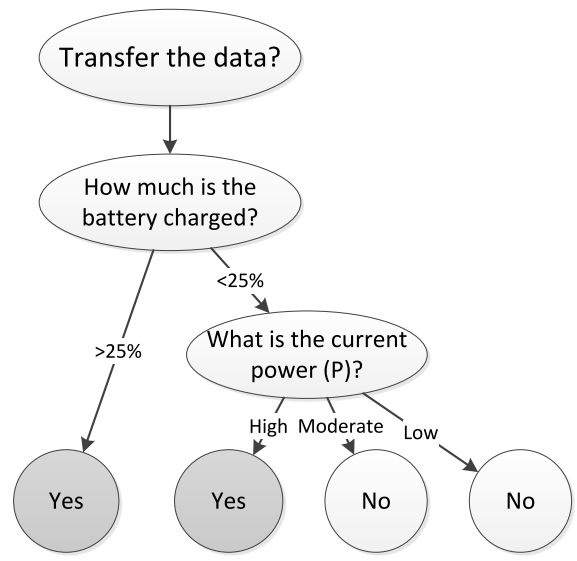

Fig. 11. The decision tree used in the energy planning component.

case of $R^{2}=1$, the model has an exact correspondence to the experimental data. Accordingly, our testing results show high match to the obtained theoretical model during training.

After the training is complete, the performance of ANFIS is determined using MSE $=$ 0.0032 (Eq. (6)). This small MSE shows the close finding to the line of best fit.

Those ANFIS results $\mathrm{P} *$ are transferred to the Energy Planning Component to make a decision for data transferring to Decision Support Subsystem. The Energy Planning Component based on the input data from ANFIS (P*) and Data Storage (P, I_PV, P_PV) decides whether to send the data. The decision mechanism is the rule-based and presented by the decision tree in Fig. 11.

According to the predefined rules, the current power $\mathrm{P}$ is estimated based on ANFIS predictions, i.e. the current power level is determined to be high, medium, or low. The bat- 
Table 4

An example of the obtained decision-making results with the proposed approach $(1-$ transfer the data, 0 - terminate the data transfer).

\begin{tabular}{llll}
\hline $\mathrm{P}$ & $\mathrm{P}^{*}$ & Battery & Signal \\
\hline 41 & Low & $25 \%$ & 0 \\
47 & High & $55 \%$ & 1 \\
50 & Moderate & $70 \%$ & 1 \\
20 & Moderate & $42 \%$ & 1 \\
36 & Low & $36 \%$ & 1 \\
45 & Moderate & $7 \%$ & 0 \\
58 & High & $24 \%$ & 1 \\
\hline
\end{tabular}

tery charging level for making the decision is chosen $25 \%$, because this level is critical ensuring the data transfer and further operation of the entire system after the data transfer.

The snapshot of the obtained decision-making results is presented in Table 4.

The major challenge for the proposed approach and its implementation is the collection of reliable data and the ability to cope with very fast changing environmental conditions. The usage of ANFIS for Smart-SolE demonstrates flexibility of the data transfer according to different environmental conditions, like shading and seasonality.

\section{Discussion}

The analysis of the related works showed that marine monitoring systems, combined with AI and IoT components for the data collection, processing, transmission and overall systems operation, become more accurate and flexible. Existing approaches are utilizing ANFIS for solar energy planning in different application domains and purposes. The review of the found and analysed smart buoy systems shows that authors mainly emphasize data transmission using IoT of buoys, rather than incorporating smart solar energy planning in buoys. Therefore, we emphasize on more detailed level of smart solar energy planning in buoys.

In this paper, the smart fuzzy inference based solar energy planning and control component (Smart-SolE) for coastal marine water monitoring has been developed and examined to validate its performance. The advantage and uniqueness of the proposed approach is that we establish an ANFIS-based model to predict and control solar energy for different lighting and temperature conditions depending on the four seasons in the Baltic Sea region in the coastal waters of Lithuania. The proposed model has been implemented in a smart fuzzy coastal marine water monitoring system (Smart-SolE) for estimation of a current power of a solar battery, lighting and temperature conditions and to make a decision using the proposed decision tree to transfer the data collected by a buoy to the Decision Support Subsystem. During the experimental research it was observed that air temperature, solar irradiance and their ratio change similarly in spring and autumn; therefore, those two seasons were combined in the experiments of the proposed approach. However, the proposed approach is universal and can be used in other regions with different seasonality, only by 
adapting the specific solar energy supply weather conditions for recognizing the specific working modes of solar energy supply.

The study shows that ANFIS is a suitable artificial intelligence model for solar energy planning and control in the coastal marine water monitoring area. The obtained accuracy of the testing is $R^{2}=0.8371$ that shows high match to the obtained theoretical model during training. The performance of ANFIS is MSE $=0.0032$, which shows the close finding to the line of best fit.

This research focused on the use of Smart-SolE for coastal marine water monitoring, limiting research on other components, like detailed buoys' physical characteristics, more detailed solar energy generation data and solar battery charging data. More real data is necessary for investigation. Moreover, the issues of the assessment of coastal marine water quality remain in our future plans. Based on these observations, further questions were raised regarding applying of artificial intelligence for improvement and extension of the decision-making component and making it smarter and more independent of user's intervention.

\section{Conclusions}

Extensive human intervention into nature and increasing environmental pollution have increased the need to study and monitor adverse effects on marine waters. In order to solve the coastal marine water monitoring tasks, different marine water monitoring systems are proposed. Nowadays, new technologies, like IoT and machine learning, allow us to improve and extend functionality of remote marine monitoring. However, the topic of intelligent solar energy (or irradiation) systems for marine quality monitoring remains insufficiently examined. In this research, the approach for solar energy implementation in remote control monitoring system of buoys was proposed. The main focus is the development of the Smart-SolE reasoning component that is integrated into the entire SmartMarineM. The novelty of Smart-SolE is the use of an ANFIS-based model, which enables more adaptable and continuous work of buoys in coastal marine monitoring processes.

From the study, based on the obtained accuracy, it was determined that ANFIS is a suitable AI model for solar energy planning and control in the coastal marine monitoring area. However, additional investigations with consideration of the buoys' physical characteristics, communication protocols, and more detailed analysis of solar battery charging process are necessary.

\section{Acknowledgements}

The authors thank Dr. Darius Daunys, Vice-Rector for Research and Innovation of Klaipèda University, and Dr. Toma Dabulevičienè, researcher at Marine Research Institute of Klaipeda University, for kind sharing of the technical specification and collected measurement data of their hydrographic buoy. 


\section{References}

Abadi, I., Imron, C., Noriyati, R.D. (2018). Implementation of Maximum Power Point Tracking (MPPT) technique on solar tracking system based on Adaptive Neuro-Fuzzy Inference System (ANFIS). E3S Web of Conferences, 43, 01014. https://doi.org/10.1051/e3sconf/20184301014.

Aghel, B., Rezaei, A., Mohadesi, M. (2019). Modeling and prediction of water quality parameters using a hybrid particle swarm optimization-neural fuzzy approach. International Journal of Environmental Science and Technology, 16(8), 4823-4832. https://doi.org/10.1007/s13762-018-1896-3.

Behmel, S., Damour, M., Ludwig, R., Rodriguez, M.J. (2016). Water quality monitoring strategies-a review and future perspectives. Science of the Total Environment, 571, 1312-1329. https://doi.org/10.1016/ j.scitotenv.2016.06.235.

Bogardi, I., Bardossy, A., Duckstein, L., Pongracz, R. (2004). Chapter 6 - Fuzzy logic in hydrology and water resources. In: Demicco, R.V., Klir, G.J. (Eds.), Fuzzy Logic in Geology. Academic Press, pp. 153-190. https://doi.org/10.1016/B978-012415146-8/50009-3.

Choi, B., Rhee, F. (2009). Interval type-2 fuzzy membership function generation methods for pattern recognition. Information Sciences, 179(13), 2102-2122. https://doi.org/10.1016/j.ins.2008.04.009.

Cho, J., Kim, M.W., Kim, Y., Park, J.-S., Lee, D.-H., Kim, Y., Kim, J.J. (2021). Seawater battery-based wireless marine buoy system with battery degradation prediction and multiple power optimization capabilities. IEEE Access, 9, 104104-104114. https://doi.org/10.1109/ACCESS.2021.3098846.

Colglazier, W. (2015). Sustainable Development Agenda: 2030. Science, 349, 1048-1050. https://doi.org/ 10.1126/science.aad2333.

Dâmaso, A., Rosa, N., Maciel, P. (2014). Using coloured petri nets for evaluating the power consumption of wireless sensor networks. International Journal of Distributed Sensor Networks, 10(6), 423537.

Darmawan, S., Irawan, B., Setianingsih, C., Murty, M.A. (2020). Design of detection device for sea water waves with fuzzy algorithm based on Internet of Things. In: 2020 IEEE International Conference on Industry 4.0, Artificial Intelligence, and Communications Technology (IAICT), pp. 75-80. https://doi.org/10.1109/ IAICT50021.2020.9172018.

Delpla, I., Benmarhnia, T., Lebel, A., Levallois, P., Rodriguez, M.J. (2015). Investigating social inequalities in exposure to drinking water contaminants in rural areas. Environmental Pollution, 207, 88-96. https://doi.org/ 10.1016/j.envpol.2015.08.046.

Demetillo, A., Japitana, M., Taboada, E. (2019). A system for monitoring water quality in a large aquatic area using wireless sensor network technology. Sustainable Environment Research, 29(12). https://doi.org/10.1186/ s42834-019-0009-4.

Demirdelen, T., Aksu, I.O., Esenboga, B., Aygul, K., Ekinci, F., Bilgili, M. (2019). A new method for generating short-term power forecasting based on artificial neural networks and optimization methods for solar photovoltaic power plants. In: Precup, R.-E., Kamal, T., Zulqadar Hassan, S. (Eds.), Solar Photovoltaic Power Plants. Springer, Singapore, pp. 165-189. https://doi.org/10.1007/978-981-13-6151-7_8.

Dzemydiené, D., Radzevičius, V. (2020). An approach for networking of wireless sensors and embedded systems applied for monitoring of environment data. In: Dzemyda, G., Bernatavičienè, J., Kacprzyk, J. (Eds.), Data Science: New Issues, Challenges and Applications, Studies in Computational Intelligence, Vol. 869, pp. 61-82. https://doi.org/10.1007/978-3-030-39250-5_4.

Dzemydienė, D., Maskeliūnas, S., Radzevičius, V. (2021). An approach of ensuring interoperability of multidimensional data warehouses for monitoring of water resources. Journal of Environmental Engineering and Landscape Management, 29(1), 9-20. https://doi.org/10.3846/jeelm.2021.14112.

European Commission (2019). Communication from the Commission to the European Parliament, the European Council, the Council, the European Economic and Social Committee and the Committee of the Regions. The European Green Deal. COM/2019/640, 24 p. https://eur-lex.europa.eu/legal-content/EN/TXT/?uri=COM\% 3A2019\%3A640\%3AFIN.

Falleni, S., Unal, D., Neerman, A., Enhos, K., Demirors, E., Basagni, S., Melodia, T. (2020). Design, development, and testing of a smart buoy for underwater testbeds in shallow waters. In: Global Oceans 2020: Singapore-US Gulf Coast, pp. 1-7. https://doi.org/10.1109/IEEECONF38699.2020.9389065.

González-Reolid, I., Molina-Molina, J.C., Guerrero-González, A., Ortiz, F.J., Alonso, D. (2018). An autonomous solar-powered marine robotic observatory for permanent monitoring of large areas of shallow water. Sensors, 18(10), 3497. https://doi.org/10.3390/s18103497. 
Gricius, G., Drungilas, D., Andziulis, A., Dzemydienè, D., Voznak, M., Kurmis, M., Jakovlev, S. (2015). Advanced approach of multiagent based buoy communication. The Scientific World Journal, 2015, 1-6. ID 569841. https://doi.org/10.1155/2015/569841.

Gudas, S. (2021). Causal modelling in enterprise architecture frameworks. Informatica, 32(2), 247-281. https:// doi.org/10.15388/21-INFOR446.

Haller, A., Janowicz, K., Cox, S.J.D., Lefrançois, M., Taylor, K., Le Phuoc, D., Lieberman, J., García-Castro, R., Atkinson, R., Stadler, C. (2019). The modular SSN ontology: a joint W3C and OGC standard specifying the semantics of sensors, observations, sampling, and actuation. Semantic Web, 10 9-32. https://doi.org/ 10.3233/SW-180320.

Helmi, A.M.A., Hafiz, M.M., Rizam, M.S. (2014). Mobile buoy for real time monitoring and assessment of water quality. In: 2014 IEEE Conference on Systems, Process and Control (ICSPC 2014), pp. 19-23. https://doi.org/ 10.1109/SPC.2014.7086223.

Hwang, S.M., Park, J.S., Kim, Y., Go, W., Han, J., Kim, Y., Kim, Y. (2019). Rechargeable seawater batteriesfrom concept to applications. Advanced Materials, 31(20), 1804936. https://doi.org/10.1002/adma. 201804936.

Ighalo, J.O., Adeniyi, A.G., Marques, G. (2021). Artificial intelligence for surface water quality monitoring and assessment: a systematic literature analysis. Modeling Earth Systems and Environment, 7, 669-681. https://doi.org/10.1007/s40808-020-01041-z.

Iqbal, M., Matulevičius, R. (2020). Corda security ontology: example of post-trade matching and confirmation. Baltic Journal of Modern Computing, 8(4), 638-674. https://doi.org/10.22364/bjmc.2020.8.4.11.

Janowicz, K., Haller, A., Cox, S., Le Phuoc, D., Lefrançois, M. (2019). SOSA: a lightweight ontology for sensors, observations, samples, and actuators. Journal of Web Semantics, 569, 1-10. https://doi.org/10.1016/j. websem.2018.06.003.

Kalibatienė, D., Miliauskaite, J. (2021). A hybrid systematic review approach on complexity issues in data-driven fuzzy inference systems development. Informatica, 32(1), 85-118. https://doi.org/10.15388/21-INFOR444.

Kambalimath, S., Deka, P.C. (2020). A basic review of fuzzy logic applications in hydrology and water resources. Applied Water Science, 10, 191. https://doi.org/10.1007/s13201-020-01276-2.

Karaboga, D., Kaya, E. (2019). Adaptive network based fuzzy inference system (ANFIS) training approaches: a comprehensive survey. Artificial Intelligence Review, 52(4), 2263-2293. https://doi.org/10.1007/s10462017-9610-2.

Kesavakumar, B., ArulMuthiah, M., Elango, S., Gowthaman, D., Kaliyaperumal, P., Senthilkumar, P., Sridharan, R., Venkatesan, R. (2013). Design of optimal power source for NIOT offshore moored buoy system. 2013 Ocean Electronics (SYMPOL), 189-195. https://doi.org/10.1109/SYMPOL.2013.6701929.

Kim, Y., Harzandi, A.M., Lee, J., Choi, Y., Kim, Y. (2021). Design of large-scale rectangular cells for rechargeable seawater batteries. Advanced Sustainable Systems, 5(1), 2000106. https://doi.org/10.1002/adsu. 202000106.

Kumar, J.K.M., Abdul Rauf, H., Umamaheswari, R. (2020). Switched capacitor-coupled inductor DC-DC converter for grid-connected PV system using LFCSO-based adaptive neuro-fuzzy inference system. Journal of Circuits, Systems and Computers, 29(12), 2050201. https://doi.org/10.1142/S0218126620502011.

Li, Y., Guo, Q., Huang, M., Ma, X., Chen, Z., Liu, H., Sun, L. (2019). Study of an electromagnetic ocean wave energy harvester driven by an efficient swing body toward the self-powered ocean buoy application. IEEE Access, 7, 129758-129769. https://doi.org/10.1109/ACCESS.2019.2937587.

Ligaray, M., Kim, N., Park, S., Park, J.S., Park, J., Kim, Y., Cho, K.H. (2020). Energy projection of the seawater battery desalination system using the reverse osmosis system analysis model. Chemical Engineering Journal, 395, 125082. https://doi.org/10.1016/j.cej.2020.125082.

Lin, Y.P., Huang, C.J., Chen, S.H., Doong, D.J., Kao, C.C. (2017). Development of a GNSS buoy for monitoring water surface elevations in estuaries and coastal areas. Sensors, 17(1), 172. https://doi.org/10.3390 /s17010172.

Liu, Z., Mohammadzadeh, A., Turabieh, H., Mafarja, M., Band, S.S., Mosavi, A. (2021). A new online learned interval type-3 fuzzy control system for solar energy management systems. IEEE Access, 9, 10498-10508. https://doi.org/10.1109/ACCESS.2021.3049301.

Miliauskaite, J., Kalibatiene, D. (2020a). On general framework of type-1 membership function construction: case study in QoS planning. International Journal of Fuzzy Systems, 22(2), 504-521. https://doi.org/10.1007/ s40815-019-00753-4. 
Miliauskaite, J., Kalibatiene, D. (2020b). Complexity in data-driven fuzzy inference systems: survey, classification and perspective. Baltic Journal of Modern Computing, 8(4), 572-596. https://doi.org/10.22364/bjmc. 2020.8.4.08.

Mofijur, M., Mahlia, T.M.I., Silitonga, A.S., Ong, H.C., Silakhori, M., Hasan, M.H., Putra, N., Rahman, S.M.A. (2019). Phase Change Materials (PCM) for solar energy usages and storage: an overview. Energies, 12(16), 3167. https://doi.org/10.3390/en12163167.

Morón-López, J., Rodríguez-Sánchez, M.C., Carreño, F., Vaquero, J., Pompa-Pernía, Á.G., Mateos-Fernández, M., Aguilar, J.A.P. (2020). Implementation of smart buoys and satellite-based systems for the remote monitoring of harmful algae bloom in inland waters. IEEE Sensors Journal, 21(5), 6990-6997. https://doi.org/ 10.1109/JSEN.2020.3040139.

Mosavi, A., Qasem, S.N., Shokri, M.B., Mohammadzadeh, A. (2020). Fractional-order fuzzy control approach for photovoltaic/battery systems under unknown dynamics, variable irradiation and temperature. Electronics, 9(9), 1455. https://doi.org/10.3390/electronics9091455.

Olivetti, E.A., Ceder, G., Gaustad, G.G., Fu, X. (2017). Lithium-ion battery supply chain considerations: analysis of potential bottlenecks in critical metals. Joule, 1(2), 229-243. https://doi.org/10.1016/j.joule.2017.08.019.

Padmanaban, S., Priyadarshi, N., Bhaskar, M.S., Holm-Nielsen, J.B., Ramachandaramurthy, V.K., Hossain, E. (2019). A hybrid ANFIS-ABC based MPPT controller for PV system with anti-islanding grid protection: experimental realization. IEEE Access, 7, 103377-103389. https://doi.org/10.1109/ACCESS.2019.2931547.

Przybysz, A., Duarte, C.M., Geraldi, N.R., Kosel, J., Berumen, M.L. (2020). Cellular network Marine Sensor Buoy. In: 2020 IEEE Sensors Applications Symposium (SAS), pp. 1-6. https://doi.org/10.1109/ SAS48726.2020.9220047.

Qin, M., Du, Z., Zhang, F., Liu, R. (2019). A matrix completion-based multiview learning method for imputing missing values in buoy monitoring data. Information Sciences, 487, 18-30. https://doi.org/10.1016/ j.ins.2019.02.057.

Sabatini, A., Zompanti, A., Grasso, S., Vollero, L., Pennazza, G., Santonico, M. (2021). Proof of concept study of an electrochemical sensor for inland water monitoring with a network approach. Remote Sensing, 13(20), 4026. https://doi.org/10.3390/rs13204026.

Sarkar, R., Kumar, J.R., Sridhar, R., Vidyasagar, S. (2021). A new hybrid BAT-ANFIS-based power tracking technique for partial shaded photovoltaic systems. International Journal of Fuzzy Systems, 1(13). https:// doi.org/10.1007/s40815-020-01037-y.

Song, M., Liu, S., Li, W., Chen, S., Li, W., Zhang, K., Wang, X. (2021). A continuous space location model and a particle swarm optimization-based heuristic algorithm for maximizing the allocation of ocean-moored buoys. IEEE Access, 9, 32249-32262. https://doi.org/10.1109/ACCESS.2021.3060464.

Tamir, D.E., Rishe, N.D., Kandel, A. (Eds.) (2015). Fifty Years of Fuzzy Logic and its Applications, STUDFUZZ, Vol. 326. Springer, Cham, 684 pp. https://doi.org/10.1007/978-3-319-19683-1.

Tao, H., Ghahremani, M., Ahmed, F.W., Jing, W., Nazir, M.S., Ohshima, K. (2021). A novel MPPT controller in PV systems with hybrid whale optimization-PS algorithm based ANFIS under different conditions. Control Engineering Practice, 112, 104809. https://doi.org/10.1016/j.conengprac.2021.104809.

Thamrin, N.M., Megat Ali, M.S.A., Misnan, M.F., Nik Ibrahim, N.N., Shaghaghi, N. (2021). Sustainable surface water dissolved oxygen monitoring at lake 7/1F, Shah Alam, Selangor. Journal of Mechanical Engineering, 8(2), 13-26. https://doi.org/10.21491/jmeche.v18i2.14940.

Trevathan, J., Sharp, T. (2020). Up-cycling e-waste into innovative products through social enterprise. In: Proceedings of the 9th International Conference on Smart Cities and Green ICT Systems - SMARTGREENS, pp. 185-193. https://doi.org/10.5220/0009350301850193.

Ullo, S.L., Sinha, G.R. (2020). Advances in smart environment monitoring systems using iot and sensors. Sensors, 20(11), 3113. https://doi.org/10.3390/s20113113.

Verma, R., Merigó, J.M. (2020). A new decision making method using interval-valued intuitionistic fuzzy cosine similarity measure based on the weighted reduced intuitionistic fuzzy sets. Informatica, 31(2), 399-433. https://doi.org/10.15388/20-INFOR405.

Viswavandya, M., Sarangi, B., Mohanty, S., Mohanty, A. (2020). Short term solar energy forecasting by using fuzzy logic and ANFIS. In: Behera, H., Nayak, J., Naik, B., Pelusi, D. (Eds.), Computational Intelligence in Data Mining. Advances in Intelligent Systems and Computing, Vol. 990. Springer, Singapore, pp. 751-765. https://doi.org/10.1007/978-981-13-8676-3_63.

Vo, D.T., Nguyen, X.P., Nguyen, T.D., Hidayat, R., Huynh, T.T., Nguyen, D.T. (2021). A review on the internet of thing (IoT) technologies in controlling ocean environment. Energy Sources, Part A: Recovery, Utilization, and Environmental Effects, 1-19 p. https://doi.org/10.1080/15567036.2021.1960932. 
W3C (2017, October 19). Semantic Sensor Network Ontology. W3C Recommendation. https://www.w3.org/ TR/vocab-ssn/.

Yetilmezsoy, K., Ozkaya, B., Cakmakci, M. (2011). Artificial intelligence-based prediction models for environmental engineering. Neural Network World, 21(3), 193. https://doi.org/10.14311/NNW.2011.21.012.

Yun, H., Xu, J., Wei, M., Guo, Z. (2015). Marine ecological knowledge management system based on ontology repository. International Journal of $u$ - and e-Service, Science and Technology, 8(2), 153-164. https://doi.org/ 10.14257/ijunesst.2015.8.2.15.

Zhang, D., Ashraf, M.A., Liu, Z., Peng, W.X., Golkar, M.J., Mosavi, A. (2020). Dynamic modeling and adaptive controlling in GPS-intelligent buoy (GIB) systems based on neural-fuzzy networks. Ad Hoc Networks, 103, 102149. https://doi.org/10.1016/j.adhoc.2020.102149.

Zhang, H., Li, C. II., Hua, Z. III., Ren, W., Gao, Y., Hao, Z. (2021). Design of aquaculture monitoring system based on LoRa and 4G network of Internet of Things. In: Thirteenth International Conference on Digital Image Processing (ICDIP 2021), Vol. 11878, p. 1187827. https://doi.org/10.1117/12.2601041.

Zhang, Y., Senthilkumar, S.T., Park, J., Park, J., Kim, Y. (2018). A new rechargeable seawater desalination battery system. Batteries \& Supercaps, 1(1), 6-10. https://doi.org/10.1002/batt.201800012.

Zimmermann, H.-J. (2001). Fuzzy Set Theory-and Its Applications. Springer, Netherlands. https://doi.org/ 10.1007/978-94-010-0646-0. 514 pp.

Zoss, B.M., Mateo, D., Kuan, Y.K., Tokić, G., Chamanbaz, M., Goh, L., Vallegra, F., Bouffanais, R., Yue, D.K.P. (2018). Distributed system of autonomous buoys for scalable deployment and monitoring of large waterbodies. Autonomous Robots, 42(8), 1669-1689. https://doi.org/10.1007/s10514-018-9702-0.

D. Kalibatienė is a full-time professor at the Department of Information Systems, Faculty of Fundamental Sciences, Vilnius Gediminas Technical University (VilniusTECH), Lithuania. In 2009, she defended a PhD in Technological Sciences, Informatics Engineering at VilniusTECH on the topic Ontology-Based Development of Domain Rules. She is the co-author of more than 45 research papers and the book Advanced Databases. She gives lectures for students on software systems engineering, supervises doctoral students, participates in the study and research projects, prepared two bachelor study programmes ("Information Systems" and "Software Engineering") and is a programme committee chair of master study programme "Information Systems Software Engineering". She delivered lectures at Palermo University (Sicily, Italy), University of La Laguna (Tenerife, Spain) and University of Ruse (Ruse, Bulgaria). Currently, D. Kalibatienè is the guest editor of a special issue of the journal Applied Sciences. She is a member of programme committee of the International Baltic Conference on Digital Business and Intelligent Systems (Baltic DB\&IS 2022). She actively reviews research papers, project applications and study work, and makes presentations in international conferences. Her research interests include modelling and development of information systems based on business rules and ontology; modelling and simulation of knowledge-based multi-objective dynamic business processes; application of multi-criteria decision-making methods to solve engineering tasks; application of fuzzy set theory to model, plan and predict the concept of quality in various subject areas.

J. Miliauskaitė is a junior researcher at Vilnius University (VU) (Lithuania) Institute of Data Science and Digital Technologies Department of Cyber-Social Systems Engineering Group. In 2015, she defended a PhD in Technological Sciences, Informatics Engineering at VU on the topic A Fuzzy Inference-Based Approach to Planning Quality of Enterprise Business Services. She is the co-author of research papers in the field of computer sciences. She is an assistant at VU Faculty of Mathematics and Informatics and 
a docent at Vilnius Gediminas Technical University (Lithuania) Faculty of Fundamental Sciences Department of Information Systems. She participated in the project of EU Structural Funds "Theoretical and Engineering Aspects of E-Service Technology Development and Application in High-Performance Computing Platforms". She is a member of organising committee of the International Baltic Conference on Databases and Information Systems (Baltic DB\&IS 2012, Baltic DB\&IS 2018). She is a member of Lithuanian Computer Society (LIKS). She reviews research papers, study work, and makes presentations in international conferences. Her research interests include enterprise business services, service-oriented enterprise systems, web service composition, quality of service modelling and evaluation in service-oriented enterprise systems; application of multi-criteria decision-making methods to solve engineering tasks; application of fuzzy set theory to model, plan and predict the concept of quality in various subject areas.

D. Dzemydienė is a professor, doctor, senior researcher working at the Cyber-Social Systems Engineering Group in the Institute of Data Science and Digital Technologies at the Faculty of Mathematics and Informatics of Vilnius University (Lithuania). She obtained a diploma with honour of applied mathematics in specialization of software engineering in $1980, \mathrm{PhD}$ of mathematics-informatics sciences in 1995, completed the habilitated doctor procedure in the field of social sciences of management and administration in 2004. She has published about three hundred research articles, three manual books and one monograph book. She is an organizer of international conferences in the area of information systems and database development. She is the head of the Legal Informatics Section of Lithuanian Computer Society (LIKS), member of European Coordinating Committee for Artificial Intelligence (ECCAI) and member of Lithuanian Operation Research Association. Her research interests include: artificial intelligence methods, knowledge representation and decision support systems, wireless computing, evaluation of sustainable development processes.

S. Maskeliūnas is a doctor of informatics sciences, working as a researcher at the CyberSocial Systems Engineering Group in the Institute of Data Science and Digital Technologies of Vilnius University, Lithuania. He has defended the diploma in engineering and system-technical sciences at the Kaunas University of Technology (1984); PhD in informatics sciences (1996). He was the co-author and the system analyst of the projects "Governmental administrative information system VADIS" (1996-1998), "Long-term assistance on information and reporting, information management programme" (2000-2001), "Transposition of the EU Water Framework Directive and Elaboration of a National Strategy for the Management of Water Resources in Lithuania" (2002), "Implementation of the EU Water Framework Directive, Lithuania, Meeting 2006 Deadlines” (2003-2004); task leader of the project "Lithuania - RTD Technological Audit: a complex study of ICT RTD potential in Lithuania" (2009-2010), National open access research data archive MIDAS (2012-2015). He is an author of about 50 research articles. His research interests: information and knowledge-based systems, ontological engineering, semantic web, web services, scientometrics, knowledge management. 